\title{
FAE BRAUER, ANTHEA CALLEN (UR.) ART, SEX AND EUGENICS: CORPUS DELECTI.
}

\author{
Aldershot, Burlington: Ashgate, 2008, 298 strani.
}

Evgenika je demografskopolitična teorija, ki stremi k izboljšanju »kvalitete« naroda, in sicer tako, da spodbuja razmnoževanje »dobrih" genov in preprečuje razmnoževanje »slabih«. Svoj zenit je doživela v prvi polovici 20. stoletja, ko so na njenih načelih v ZDA, na Švedskem, v Nemčiji in še v nekaterih državah uvajali prisilne sterilizacije domnevno »manjvrednih« ljudi. Njeno skrajno obliko je predstavljal nacistični pogrom nad Judi.

Zaradi sence nacističnih zločinov je po 2. svetovni vojni evgenika izgubila na veljavi. Tudi o njeni zgodovini se dolgo ni veliko pisalo. Ob upoštevanju prostorskih razlik in novih teoretičnih pristopov, zlasti tistih, ki jih je razvil Michael Foucault, se je nato pokazala izredna pomembnost te historične tematike. $\mathrm{V}$ zadnjem času so tako izšle številne študije, ki evgeniko osvetljujejo $\mathrm{z}$ različnih zornih kotov, toda le malo izmed njih tako resno vzame $\mathrm{v}$ pretres njeno umeščenost $\mathrm{v}$ polje vizualnih medi- jev ter s tem izpostavi nujnost njene umetnostnozgodovinske interpretacije kakor knjiga Art, Sex and Eugenics: Corpus Delecti.

$\mathrm{V}$ navedenem delu osem različnih avtorjev, povečini umetnostnih zgodovinarjev, analizira povezave med vizualnim in evgeniko. Prispevki si sledijo po kronološkem zaporedju, od približno leta 1740 do leta 1945 , in posamično obravnavajo področja Severne Amerike, Francije, Nemčije, Sovjetske zveze, Avstralije, Nove Zelandije in Velike Britanije, kar po svoje priča o globalnosti tega fenomena.

V (pod)zavest ljudi so evgenične ideje pronicale skozi množico različnih mehanizmov. V knjigi so pod drobnogled vzeti tisti, ki so se vezali na telo (na kar nakazuje tudi poudarek besedne zveze corpus delecti, izpostavljene v podnaslovu). Svojo izbiro avtorji utemeljujejo v vplivni Foucaultovi teoriji o naravi moderne oblasti, ki naj bi delovala prav prek 
nadzorovanja ter discipliniranja teles in telesnih gibov. Beseda »delecti« nadalje označuje, da gre pri njihovi analizi v veliki meri za posebno telo - za prijetno, očarljivo in predvsem erotično telo. Toda ali je ars erotico sploh možno povezati s scientio sexualis, kakršno predstavlja evgenika? Mar divji, neracionalni spolni nagon ni v nasprotju z demografskopolitično teorijo, ki razmnoževanje racionalizira? Avtorji pričujočega dela na to vprašanje odgovorijo negativno. Pri tem se ponovno sklicujejo na Foucaulta, ki predpostavlja, da biopolitični mehanizmi pogosto stimulirajo prav tiste strasti, ki jih deklarativno prepovedujejo. Kot izredno pomembno se izkaže njihovo osredotočanje na umetnost, za katero velja, da s svojo zmožnostjo vdora v podzavestno vpliva na čutne in čustvene preference. Skozi večino študij obravnavanega dela tako sledimo tezi, da so s poudarjanjem erotične privlačnosti arijskega telesa vizualni mediji ključno prispevali k uresničevanju evgeničnih ciljev - evgenika je prek njih delovala seduktivno.

Evgenične ideje so se sicer začele uveljavljati še preden je Francis Galton leta 1883 skoval ta termin. Na to bralca opozarja že Roger Blackley, ki v prvem poglavju obravnava simbolne pomene impresivnega maorskega plesa Hake. Blackley ob analizi starih etnografskih tekstov iz 18. in 19. stoletja namreč ugotavlja, da je zahodna psevdoznanost maorske plesne gibe brala kot patološke, sprevržene in degenerirane ter jih tako prištevala med dokazno gradivo vse bolj vplivnega socialnega darvinizma, s katerim je upravičevala proces izumiranja novozelandskih domorodcev.

Shawn Michelle Smith, avtor drugega poglavja, pozornost $\mathrm{z}$ rasističnih interpretacij preusmeri na samoopredelitve tistih, ki jih je severnoameriška evgenika z začetka 20 . stoletja poskušala stlačiti v kategorijo »dedno manjvrednih «. V tem kontekstu analizira portrete črncev, ustvarjenih s strani temnopoltih avtorjev. Zanimive so mu zlasti upodobitve, ki jih je leta 1900 na svetovni razstavi v Parizu predstavil temnopolti sociolog William Edward Burghardt du Bois, saj so kopirale tehnike "rasne» antropometrične fotografije, in to $\mathrm{z}$ namenom, da bi njihovo znanstveno vrednost postavile na laž.

Medtem ko prva dva avtorja, gledano iz perspektive tedanjih evgenikov, postavljata na ogled telo drugega, se Fae Brauer v tretjem poglavju usmeri v analizo strategij, $s$ katerimi je francoska oblast v času Tretje republike disciplinirala telo državljana, ki je predstavljalo normo. Francoska 
znanstvena srenja je upoštevala načela t. i. neolamarckianske evgenike. Ta se je v nasprotju z Galtonovo evgeniko, značilno na primer za ZDA, bolj kot na dedne lastnosti prednikov osredotočala na kvarne učinke okolja. Da bi odvrnili grožnjo pred evgeničnim propadom, so francoski evgeniki poudarjali pomen zdravega telesa, spodbujali športno udejstvovanje ter se spustili v boj proti slabim higienskim razmeram, alkoholizmu in predvsem nenadzorovani seksualnosti. Ker so skušali spolno aktivnost kanalizirati v okvire monogamnega zakona, ki naj bi državi zagotavljal rojstva zdravih in obenem številnih otrok, so cenzurirali kontracepcijo, pornografijo in celo erotično umetnost. Toda brž ko je erotična golota sledila trendom upodabljanja popolnega neolamarckianskega telesa, je ostajala necenzurirana. Po mnenju avtorice je zato jasno, da francoski evgeniki spolnega poželenja niso zatirali, ampak ga le preusmerjali stran od domnevno degeneriranega telesa prostitutke k zdravemu, lepemu telesu evgenično popolnega posameznika oziroma posameznice.

V četrtem poglavju Anathea Callen sledi razvoju upodobitev človeka stroja, ki od anatomskih skic iz 18 . stoletja do sodobnih znanstvenofantastičnih načrtov o izdelavi kiborga ostaja nujno spolno in razredno definiran, saj se ga vselej riše v obliki delujočega moškega telesa (delavca). Učinki tovrstnih predstav se po njenem mnenju kažejo $\mathrm{v}$ zastiranju običajnosti smrtnih teles in njenem simbolnem nadomeščanju s heroičnim rambovskim glamurjem, neranljivostjo in iluzijo nesmrtnosti. $\mathrm{V}$ nasprotju $\mathrm{z} v$ predhodnem poglavju opisanimi upodobitvami moški corpus delecti pri tem ne služi kot vaba ženskemu reproduktivnemu nagonu, temveč draži homoerotično ali avtoerotično moško željo po lastni popolni lepoti in, lahko bi rekli, učinkovitosti.

Tudi Gabriel Koreaus, avtor petega poglavja, v središču pozornosti ohranja idealizirana moška telesa, kakršna so prikazovali britanski filmi, literatura in revije iz obdobja med obema vojnama. Interpretira jih v smislu odgovora na travme iz prve svetovne vojne. Po njegovem mnenju je njihova popolna in celostna lepota namreč delovala kot obrambni mehanizem, s katerim so se mediji postavljali nasproti grozljivim prizorom razmesarjenih udov $\mathrm{z}$ bojišča.

$\mathrm{V}$ šestem poglavju se Lorettann Gescard v nasprotju s prvimi petimi avtorji in avtoricami posveti izključno obravnavi ženskega tele$\mathrm{sa}$, in sicer $\mathrm{v}$ povezavi $\mathrm{z}$ evgenični- 
mi aspiracijami Hitlerjeve Nemčije. Kakor ugotavlja, je nacionalsocializem nihal med dvema povsem različnima idealoma ženske - med t. i. »evgeničnim idealom « in t. i. »všečnim idealom«. »Evgenični ideal« se je skladal s podobo dobre nemške žene, ki je pohlevno sledila svojemu možu ter domovini rojevala otroke. Toda čeprav je tako telo služilo interesom države, je bilo zaradi številnih rojstev nujno $\mathrm{v}$ nasprotju s podobo skladnega in zapeljivega arijskega telesa filmskih starlet, ki je vzbujalo erotične želje nacistov in bi ga lahko označili kot "všečen ideal«. Tovrstne razlike v dojemanju "popolne" ženske se zrcalijo tudi skozi tedanja umetniška dela, med katerimi se zdi, da so najbolj neslavno propadla prav tista, ki so stremela knemogoči združitvi obeh idealov v eno podobo.

$\mathrm{Na}$ načine dojemanja in discipliniranja ženskega telesa se osredotoča tudi sedmo poglavje. V njem se namreč Pat Simpson poda v interpretacijo pomenov propagandnih plakatov, letakov in fotografij, s katerimi je v obdobju med obema vojnama ženske naslavljala sovjetska oblast. Prav tako kot na zahodu je bilo tudi v Sovjetski zvezi materinstvo dojeto kot osrednja dolžnost žensk nasproti državi in tudi tu so tovrstnim poudarkom sledili pozivi $\mathrm{k}$ evgeniki ter predvsem evteniki (zdravstvenemu razsvetljevanju), s katerimi si je oblast prizadevala producirati zdrava in uporabna telesa. Od sovjetske ženske pa se ni pričakovalo, da je pri izgradnji nove prihodnosti sodelovala samo v vlogi matere, ampak se je morala angažirati tudi kot (javna) delavka. V tem kontekstu so mediji risali razlike med pretirano seksapilno hčerko kapitalizma in novim tipom proletarke, ki naj bi zahodne potrošniške lepotne ideale nasprotno zavračala in svojo spolno energijo usmerjala v delo. Podobno kot v francoskem primeru je tudi sovjetski oblasti vizualno služilo kot instrument pri upravljanju s spolnostjo - z njim je gradila kult dela.

$\mathrm{V}$ zadnjem poglavju eksponati newyorške svetovne razstave, organizirane leta 1939, ponudijo še izhodišče za analizo ameriških predstav o videzu »superčloveka prihodnosti«, v katerih Cristina Cogdel prepoznava izrazite podobnosti $\mathrm{z}$ iskanjem popolnega industrijskega oblikovanja. Dizajniranje ljudi in dizajniranje predmetov namreč združuje vera $\mathrm{v}$ zmožnost obvladovanja narave, toda hkrati tudi nelagodje ob neuspehu točne definicije in nato dejanske realizacije »idealnega .

Kljub tematski in prostorski razpršenosti delo Art, Sex and Eugeni- 
cs: Corpus Delecti ponuja številne vsebinske iztočnice, med katerimi bodo nekatere tudi ožje zanimive za slovenske raziskovalce. Opisa francoske neolamarckianske evgenike in sovjetske evtenike na primer pripomoreta $\mathrm{k}$ razumevanju teoretičnega ozadja, na katerega so se v preteklosti opirali slovenski privrženci tovrstnih idej. Ti so prav tako veliko pozornosti posvečali vplivu okolja oziroma »zdravstvenemu razsvetljevanju«. Poleg tega poglavje o Sovjetski zvezi predstavi (in po svoje interpretira) nekatere avtorje, o katerih je v obdobju med obema vojnama razmeroma veliko pisal slovenski ženski tisk (gl. na primer odstavek o Antonu Nemilovu). Onstran partikularnih nacionalnih in historičnih okvirov pa se dodana vrednost obravnavanega dela kaže predvsem $v$ razkrivanju latentnega, vendar še danes aktualnega delovanja vizualnih medijev, ki so mnogokdaj v službi oblastnih mehanizmov, saj s tehniko erotičnega zapeljevanja pripomorejo $\mathrm{k}$ prikritemu oblikovanju arbitrarnih družbenih vlog. 